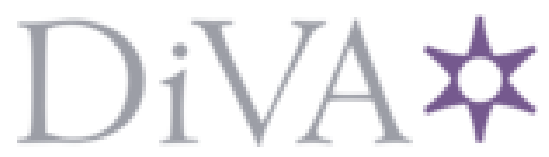

http://www.diva-portal.org

\title{
Postprint
}

This is the accepted version of a paper published in Nature Geoscience. This paper has been peerreviewed but does not include the final publisher proof-corrections or journal pagination.

Citation for the original published paper (version of record):

Mendonca, R., Kosten, S., Sobek, S., Barros, N., Cole, J. et al. (2012)

Hydroelectric carbon sequestration.

Nature Geoscience, 5(12): 838-840

http://dx.doi.org/10.1038/ngeol653

Access to the published version may require subscription.

N.B. When citing this work, cite the original published paper.

Permanent link to this version:

http://urn.kb.se/resolve?urn=urn:nbn:se:uu:diva-187353 


\section{Hydroelectric carbon sequestration}

To the Editor - The number of hydroelectric dams has increased rapidly in the past two decades and so, too, has the world's interest in their environmental effects ${ }^{1}$. Hydroelectricity is not free from greenhouse-gas emissions ${ }^{2}$ and, in particular, methane release from dams has been identified as an important contributor to global warming ${ }^{3}$. However, most greenhouse-gas assessments neglect the idea that hydroelectric reservoirs are also large carbon sinks and can sequester organic carbon in their sediments ${ }^{4}$. We argue that the common practise of neglecting carbon burial in hydroelectric reservoirs leads to an erroneous characterisation of the effect of river damming on the carbon cycle.

Organic carbon in sediments represents carbon dioxide that has been removed from the atmosphere by photosynthesis on land or in water. The fraction of organic carbon that escapes mineralisation - that is, the microbial transfer of organic carbon back into carbon dioxide or methane - accumulates and is buried. This process therefore represents a sink for atmospheric carbon. The typically intense inputs of fluvial sediments containing organic carbon and the high trapping efficiency of dams make hydroelectric reservoirs important sites for organic carbon burial ${ }^{5}$.

To fully assess the impact of damming rivers on the carbon budget requires that both carbon burial and emissions prior to impounding are considered. Burial in a reservoir only represents an effective sink for carbon in cases where: (i) in the absence of the dam, the organic carbon would not have later been buried downstream or in the ocean anyway; or (ii) the buried organic carbon is derived from new production in the reservoir. If these conditions are not met, the burial of landderived organic carbon in the reservoir is, in part, just a matter of changing the location of storage. 
In reservoirs, sediment-deposition rates are high, and the exposure of deposited organic carbon particles to oxygen in the overlaying water is limited as they are rapidly covered by new particles $^{6}$. Moreover, bottom water oxygen levels are frequently low as stratification prevents atmospheric oxygen to reach bottom waters. The mineralization of organic carbon is more efficient in oxygenated waters, and therefore the burial of organic carbon in reservoirs is increased relative to rates of burial in the more oxygenated sediments commonly found in floodplain lakes or the ocean ${ }^{6}$. This suggests that in the absence of the dam, a greater fraction of the organic carbon carried by the river would be mineralised and released to the atmosphere as carbon dioxide.

Precise estimation of carbon emission versus burial in hydroelectric reservoirs is, however, complicated by unknown and unconstrained factors that operate over variable timescales. Firstly, when the reservoir fills up with water, terrestrial organic matter that is hard to decompose such as tree trunks and organic soil adds to the reservoir's organic carbon stock representing a type of burial. In a tropical Brazilian reservoir, for example, large tree trunks still emerge from the water surface, 23 years after impounding ${ }^{7}$. In addition, some organic carbon in reservoir sediments may come from carbon-dioxide fixation by primary producers originating within the reservoir itself, e.g. phytoplankton $^{8}$. This process represents an additional carbon sink, but the quantification of its effect requires better estimates of the proportion of locally-derived organic carbon to that carried from external sources. Aquatic organic carbon is readily degradable, even in anoxic conditions, so largescale carbon-dioxide fixation by primary producers within the reservoir could ultimately fuel microbes that create methane. Moreover, most hydroelectric reservoirs are net heterotrophic ${ }^{9}$, meaning that more carbon dioxide is released from the waters than is taken up by photosynthetic organisms. This implies that at least some of the terrestrial organic carbon input is not buried, but decomposed within the reservoir. 
Part of the complexity associated with estimating carbon budgets in hydroelectric reservoirs stems from the fact that carbon emission and sediment burial are intimately linked. Increased terrestrial carbon loads, for example, from deforestation or increased precipitation, will elevate both carbon emissions to the atmosphere and burial in the sediment. On the other hand, factors that reduce organic carbon mineralization in sediments, such as a decrease in oxygen or temperature, cause burial to increase ${ }^{10}$ with an opposite effect on emission. Consequently, organic carbon burial may alleviate greenhouse-gas emissions from reservoirs (Fig. 1). For example, at the highly emitting Lake Wohlen reservoir in the Aare river in Switzerland, organic carbon burial was measured at 4,070 $\mathrm{g} \mathrm{CO}_{2}$-equivalent $\mathrm{m}^{-2} \mathrm{yr}^{-1}$, which is 2.7 times higher than its measured greenhouse-gas emissions ${ }^{11}$. On a global scale, the estimated rate of organic carbon burial in reservoirs is $1,464 \mathrm{~g} \mathrm{CO}_{2}$-equivalent $\mathrm{m}^{-2} \mathrm{yr}^{-1}$ (all reservoir types) ${ }^{5}$, almost twice their estimated emission rate of $810 \mathrm{~g} \mathrm{CO}_{2}$-equivalent $\mathrm{m}^{-2} \mathrm{yr}^{-1}$ (hydroelectric reservoirs only) ${ }^{9}$. Although there is no global estimate for organic carbon burial for hydroelectric reservoirs only, it is evident that without burial in hydroelectric reservoirs, greenhouse-gas emissions would likely be even larger.

The importance of organic carbon burial in reservoirs was first discussed at least three decades ago ${ }^{12}$, but we have advanced little since then, and the magnitude of the carbon sink created by hydroelectric reservoirs is still unclear. The most commonly reported estimate of organic carbon burial in reservoirs ${ }^{5}$ is derived from non-standardized methods and additional measurements in hydroelectric reservoirs seem to be limited to one tropical ${ }^{8}$ and one temperate ${ }^{11}$. The lack of organic carbon-burial data may stem, in part, from difficulties associated with accurately measuring sediment accumulation rates across entire reservoir basins that experience highly heterogeneous deposition. The evidence so far indicates that in reservoirs in colder regions, carbon burial 
outweighs emission to the atmosphere, while in warm regions such as the Amazonian biome, carbon emissions are probably higher (summarized in Fig. 1).

The area covered by hydroelectric reservoirs - currently almost as large as Germany ${ }^{9}$ - is steeply increasing due to the ever growing world's demand for (hydro)electricity. The net effect of damming rivers on the carbon cycle is however still unclear and requires the combination of preand post-flooding assessments. Although assessment of the carbon sink created by hydroelectric reservoirs is, at present, not straightforward, this sink does constitute an important component of the carbon budget and should not be neglected.

Raquel Mendonça ${ }^{1}$, Sarian Kosten ${ }^{2}$, Sebastian Sobek ${ }^{3}$, Nathan Barros ${ }^{1}$, Jonathan J. Cole ${ }^{4}$, Lars Tranvik $^{3}$, Fábio Roland ${ }^{1 *}$

*Corresponding author: fabio.roland@ufjf.edu.br

(1) Federal University of Juiz de Fora, Juiz de Fora, MG, 36036-900, Brazil;

(2) Department of Aquatic Ecology and Water Quality Management, Wageningen University, Wageningen, 6700-AA, The Netherlands

(3) Limnology, Department of Ecology and Genetics, Uppsala University, Uppsala, SE75236 Sweden;

(4) Cary Institute of Ecosystem Studies, Millbrook, New York, 12545-0129, USA; 


\section{References}

1. Wehrli, B. Renewable but not carbon-free. Nat. Geosci. 4, 585-586 (2011)

2. St Louis, V. L., Kelly, C. A., Duchemin, E., Rudd, J. W. M. \& Rosenberg, D. M. Reservoir surfaces as sources of greenhouse gases to the atmosphere: A global estimate. Bioscience 50, 766-775 (2000).

3. Giles, J. Methane quashes green credentials of hydropower. Nature 444, 524-525 (2006).

4. Stallard, R. F. Terrestrial sedimentation and the carbon cycle: Coupling weathering and erosion to carbon burial. Global Biogeochem. Cycles 12, 231-257 (1998).

5. Dean, W. E. \& Gorham, E. Magnitude and significance of carbon burial in lakes, reservoirs, and peatlands. Geology 26, 535-538 (1998).

6. Sobek, S. et al. Organic carbon burial efficiency in lake sediments controlled by oxygen exposure time and sediment source. Limnol. Oceanogr. 54, 2243-2254 (2009)

7. Fearnside, P. M. \& Pueyo, S. Greenhouse-gas emissions from tropical dams. Nat. Clim. Change 2, 382-384 (2012).

8. Kunz, M. J. et al. Sediment accumulation and carbon, nitrogen, and phosphorus deposition in the large tropical reservoir Lake Kariba (Zambia/Zimbabwe). J. Geophys. Res., [Biogeosci.] 116, 0148-0227 (2011).

9. Barros, N. et al. Carbon emission from hydroelectric reservoirs linked to reservoir age and latitude. Nat. Geosci. 4, 593-596 (2011). 
10. Gudasz, C. et al. Temperature-controlled organic carbon mineralization in lake sediments. Nature 466, 478-U3 (2010).

11. Sobek, S., Delsontro, T., Wongfun, N. \& Wehrli, B. Extreme organic carbon burial fuels intense methane bubbling in a temperate reservoir. Geophys. Res. Lett. 39, 0094-8276 (2012).

12. Mulholland, P. J \& Elwood, J.W. The role of lake and reservoir sediments as sinks in the perturbed global carbon cycle. Tellus 34, 490-499 (1982).

13. Roland, F. et al. Variability of carbon dioxide flux from tropical (Cerrado) hydroelectric reservoirs. Aquat. Sci. 72, 283-293 (2010).

14. Mendonça et al. Organic carbon burial in a large tropical hydroelectric reservoir: An integrative approach using a seismic survey. Submitted to J. Geophys. Res., [Biogeosci.] 


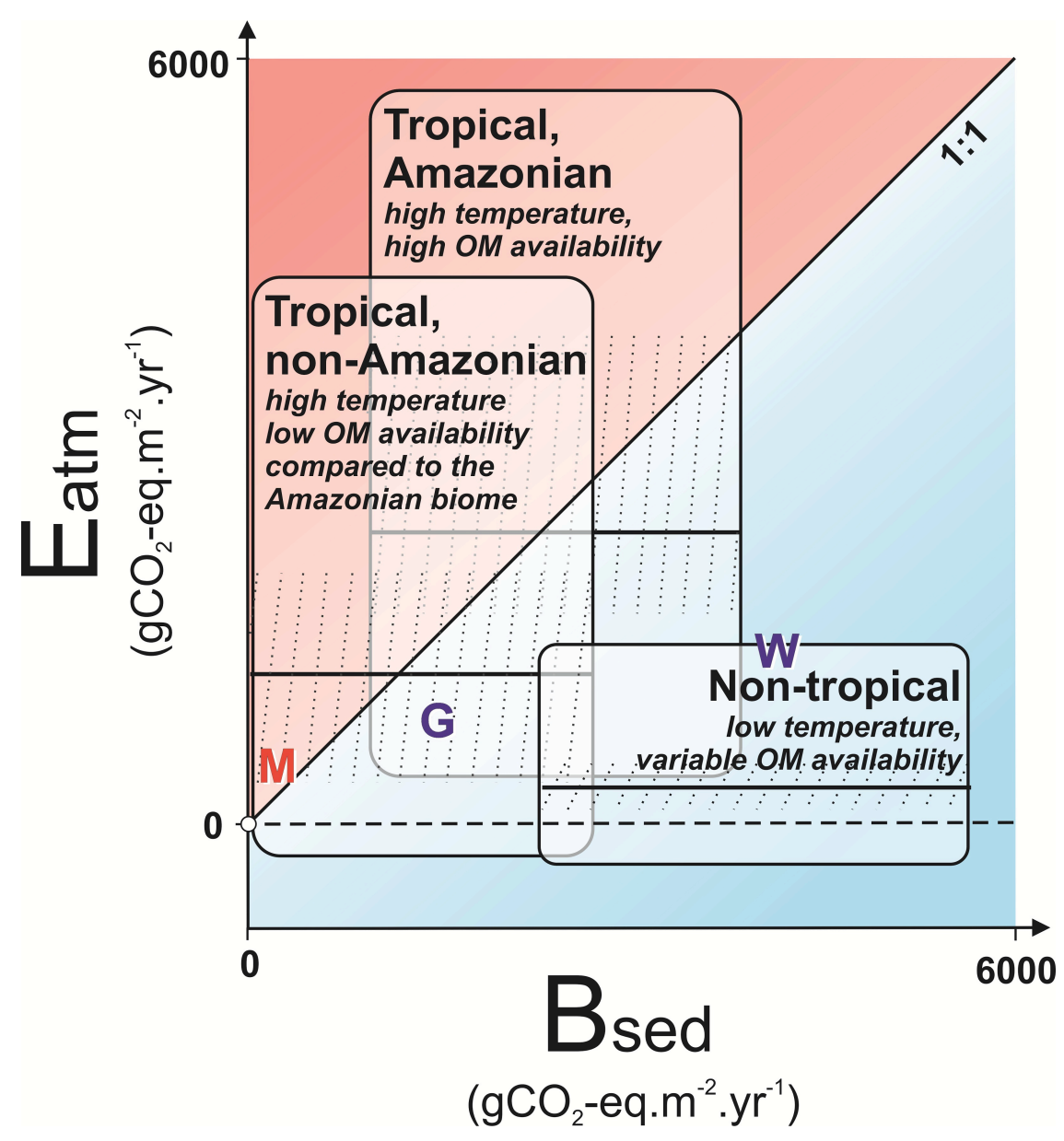

Figure 1. A conceptual model of the relationship between carbon emission to the atmosphere $\left(E_{a t m}\right)$ and organic carbon burial $\left(B_{\text {sed }}\right)$ of hydroelectric reservoirs. Only a small portion of the world's reservoirs is a net sink of atmospheric $\mathrm{CO}_{2}$-equivalents (here shown as $\mathrm{E}_{\mathrm{atm}}<0$ ) ${ }^{9}$. The range of estimates of organic carbon burial is based on the effect of temperature and organic matter availability on carbon burial. Burial rates exceeding emissions (in blue) are expected in non-tropical regions as a consequence of low mineralization rates. Burial rates in Amazonian reservoirs are thought to be higher than in other tropical regions, where emissions are expected to exceed burial (in red) because of higher organic matter availability. Dotted lines $=75 \%$ quartile; horizontal solid lines = median; M, Mascarenhas de Moraes Reservoir, Brazil ${ }^{13,14} ; \mathbf{W}$, Lake Wohlen, Switzerland ${ }^{11}$; 
G, global relationship between carbon emission and burial (from hydroelectric ${ }^{9}$ and all reservoirs ${ }^{5}$, respectively). 